\section{Computer and information}

\section{G119 STRE@MLINE >> A CHILD-CENTRED WARD COMPUTER PROGRAMME INTEGRATING SERVICE AND TRAINING}

I.D. Spillman, A. Kirk. Macclesfield District General Hospital, Cheshire, UK

Aims: To improve quality of care of In-Patients and training of Staff, enhancing safety and communication.

Methods: Stre@mLine is written in Microsoft Access 97 combining a database of admissions with real-time Clinical Governance prompts. It is very flexible allowing easy update of warnings and other data.

Results: Stre@mLine produces:

- A safe take-home prescription

- An immediate Discharge letter facilitating communication with other health professionals within both hospital and Community

- A summary for Parents explaining diagnosis, medication and follow-up in lay terms. This can be translated automatically for families whose first language is not English [two languages currently].

- On-screen prompts and warnings for staff directly related to the diagnosis and medication of the child. Lessons from risk management can be incorporated.

- $100 \%$ prospective collection of audit data with immediate reports or statistics

- Pharmacy monitoring of drug errors to allow targeted feedback

- Journal References linked to each diagnosis

- Anonymous Education / Training Portfolio sheet for staff to add learning points

- Record of previous admissions [valuable when notes unavailable]

- On-screen reference centiles for weight and body mass index

- List of children on the Hospital-at-home scheme, Open Access and In-Patients.

Conclusions: We have received encouraging feedback from parents, GPs, Community health council and defence organisations. Stre@mLine represents real-time Clinical governance in practice, particularly valuable for new Staff and integrates training with everyday clinical work.

\section{G120 COPING WITH WINTER PRESSURES: DEVELOPMENT OF A HOSPITAL-WIDE CLINICAL PRESSURES ALERT SYSTEM TO INTEGRATE CO-ORDINATED RESPONSES ACROSS CLINICAL DEPARTMENTS AND SUPPORT SERVICES}

J.O. Beattie. Department of Emergency Medicine, Royal Hospital for Sick Children, Glasgow G3 8Sf, Scotland, UK

Background: Paediatric medical services experience a surge in activity during the winter. Over some years we had developed a multi-specialty and support services winter plan to maximise our ability to cope with 50 acute secondary referrals daily while minimising disruption of elective work. However, the onset of the increase in demand is unpredictable, activating a co-ordinated service reorganisation is difficult, and involves ad hoc responses and co-operation from less pressed services.

Aim: We wished to develop a more responsive process that all hospital staff would feel part of. During periods of peak demand it would deliver an automatic integrated response across clinical and support services without the need for repeated negotiation and agreement when changes were required. All staff would know the level of clinical pressure.

Methods: A multidisciplinary project group reviewed winter planning over the preceding four years. We linked actual weekly clinical demand and system capacity using historical data, agreeing mechanisms to track acute referrals and ward capacity. We identified areas of previous difficulty. The group agreed integrated sequential responses across clinical specialties and support services and the mechanism to inform staff.
Results: We developed a 5-level colour-coded clinical pressure alert system based on an alpine avalanche risk warning system appropriate for use throughout the year. Alert levels are displayed on the network log-on screen.

Discussion: Pre-arranged system responses reduce the stress of cross-specialty negotiation when the hospital is under pressure. Knowing the alert level allows staff to take account of the bigger picture when organising clinical activity.

\section{G121 IS INTERNET ASSISTANCE WITH ACUTE PAEDIATRIC DIAGNOSIS FEASIBLE? A PILOT EVALUATION OF THE 'ISABEL' DIAGNOSTIC TOOL}

P. Ramnarayan, R.C. Tasker ${ }^{1}$, A. Reeve, G. Wilson, S. Nadel, J. Britto. St Mary's Hospital, Paddington, London; ${ }^{1}$ University of Cambridge Medical School, Addenbrookes Hospital, Cambridge, UK

Background: Medical error leads to nearly 40,000 deaths in the UK each year. Lack of easy access to relevant point-of-care information may contribute to diagnostic error by emergency medical staff.

Aims: To evaluate the performance of an Internet-based diagnostic tool (Isabel Diagnostic Tool, IsDT; Charity site, www.isabel. org.uk) in generating differential diagnoses for a given set of clinical features.

Methods: Junior medical staff from a paediatric Infectious Disease unit submitted forms with a set of clinical features and the final diagnosis/es of patients. These clinical features were entered into the IsDT and the output was compared to expected diagnosis/es. The IsDT output was derived from software (Autonomy) which understands, categorises, and searches for information by context, rather than by word. The software had been primed with Nelson's Textbook of Paediatrics $\left(15^{\text {th }}\right.$ edition). The presence of the correct diagnosis (or at least $50 \%$ of the differential provided) in the first 10 choices of the IsDT output was considered accurate.

Results: Out of a total of 81 forms used for analysis, $46(56.8 \%)$ suggested a single diagnosis as the appropriate answer and $35(43.2 \%)$ listed a differential as possible answers. The IsDT provided accurate results in $61(75.3 \%)$ out of the 81 forms, and in $40(87 \%)$ out of the 46 forms that asked for a single diagnosis.

Conclusions: The IsDT provided clinically relevant and reasonable differential diagnoses, with an accuracy of $75-87 \%$. We believe that extending the use of such a tool to a near-patient setting would greatly enhance the emergency paediatrician's diagnostic skills and serve as a real-time educational aid.

\section{G122 A COMPUTER ASSISTED LEARNING ROOM (CALR) WEBPAGE: AN INVALUABLE POINT OF REFERENCE IN UNCHARTED INTERNET TERRITORY}

P. Ramnarayan, C. Erdal. Colchester General Hospital, Colchester, Essex, UK

Background: The establishment of a CALR at the Post-Graduate Medical Centre at Colchester attracted a swarm of eager novice paediatricians vying to use the 7 Internet-ready computers. Was there a way to streamline their wayward approaches to finding medically relevant websites and increase their productivity?

Aims: To develop and maintain a readily accessible website that acted as the start page on all 7 computers, which would provide links to most paediatric and other medical websites as well as providing information on the activities of the CALR.

Methods: Using Microsoft FrontPage 2000, a large website was developed with 3 main sections: links to paediatric and other medical sites with brief descriptions of their content; CALR activities and training opportunities; and information regarding Colchester's attractions. All links opened in a separate frame to enable users to continue navigating with the original CALR webpage. A feedback form was added to collect users' views.

Results: Attendance to the CALR doubled. All users found the start page an extremely useful navigational tool, enabling them to avoid getting lost in the maze of the Internet. CALR activities received more attention.

Conclusions: The Internet novice finds surfing on the Internet for specific information (paediatric and other medical) a disappointing waste of time. Useful starting points to guide the exploration are essential to ensure that maximum benefit can be extracted from the vast store of medical information that exists on the Internet. 


\section{G123 DEVELOPMENT OF A COMPUTERISED TOUCH-SCREEN VERSION OF A QUESTIONNAIRE TO MEASURE QUALITY OF LIFE (QOL) IN CHILDREN WITH INFLAMMATORY BOWEL DISEASE (IBD)}

L. Sage ${ }^{1}$, H. Loonen ${ }^{2}$, H.H. Derkx ${ }^{2}$, D. Scott', B. Heaver ${ }^{3}$, A.G. Thomas' ${ }^{1}$. ${ }^{1}$ Booth Hall Childrens Hospital, Manchester; ${ }^{2}$ Academic Medical Centre, Amsterdam; ${ }^{3}$ Streets Heaver Healthcare Computing

Introduction: A questionnaire to measure QoL in children with IBD (IMPACT) has been developed in Canada. Some questions were felt (by children, parents and doctors) to be too complicated or upsetting. These have been simplified and made more user-friendly (IMPACTII). The questions are answered on a Visual Analogue Scale (VAS) which is time consuming and difficult to analyse, limiting its usefulness in clinical practice.

Aims: To develop a touch-screen computerised version of the IMPACT II questionnaire suitable for the clinical setting with rapid analysis of results.

Methods: The IMPACT-II questionnaire was adapted onto a Fujitsu Siemens B Series Lifebook by Streets Heaver Healthcare Computing.

Results: The computer is portable and can be easily transported to the bedside or outpatient clinic. It incorporates touch-screen technology so that children can answer questions by simply touching the screen along the VAS Line. The QoL score is calculated instantaneously c.f. 10-20 minutes for manual scoring of the paper questionnaire.

Conclusions: Questionnaires to measure QoL should provide valuable information about the impact of the illness on the childs life. These questionnaires have not been suitable for the clinical setting and have been more suited to research. The adaptation of the IMPACT-II questionnaire onto a touch-screen portable computer is a major step towards providing rapid information about $\mathrm{QoL}$ in the clinical setting. Further studies are required to see if this information $\mathrm{s}$ valid, reliable and can be used to improve the childs QoL.

\section{G124 A PILOT STUDY TO EVALUATE A MULTIMEDIA PACKAGE FOR CHILDREN WITH ASTHMA}

A. McPherson 1 , I. Crook ${ }^{2}$, C. Glazebrook ${ }^{1}$, D. Forster ${ }^{3}$, C. James ${ }^{3}$, A. Smyth ${ }^{3} .{ }^{1}$ Dept Behavioural Science, University of Nottingham; ${ }^{2}$ Showme Multimedia; ${ }^{3}$ Dept Paediatrics, Nottingham City Hospital, UK

Introduction: The impact of asthma on children's lives and those of their families can be immense. Children \& families must often follow a complicated regime of medications, monitoring and responding appropriately to physiological changes, as well as adapting the home environment and activities in order to avoid triggers. Misunderstanding often leads to non-compliance. Traditional educational programs require significant staff input, regular commitment by children \& families, and low levels of literacy often limits the use of written materials. The use of multimedia offers exciting new possibilities.

Aims: To investigate information needs of children with asthma and evaluate effectiveness of computer program in improving knowledge.

Methods: Children aged 7-14 attending a paediatric asthma clinic were invited to use the computer program, 'The Asthma Files', which uses a 'secret agent' theme to deliver information about the causes, treatments and self-management of asthma. The program allows role playing in a safe environment, and uses quizzes and interactions to reinforce key messages. 10 children (median age 11 years, range 7-14 years) were observed using the program and were asked about triggers of asthma before and after using the program.

Results: Initial levels of knowledge in the children were low. All children reported enjoying the program, and felt it was useful and interesting. After using the program, children could name significantly more triggers $(T=0, p<0.005)$.

Conclusions: Children with asthma have important information needs which may not presently be met. Our multimedia package appears to be an appropriate tool for educating children in a clinic setting. Children's knowledge of specific medical information has been shown to improve through using the program. There are plans now to evaluate the program in a randomised, controlled trial, compared with an asthma nurse delivered educational package.

\section{G125 COMPARING A DOCTOR BASED AND PHARMACY BASED COMPUTER SYSTEM FOR NEONATAL PARENTERAL NUTRITION PRESCRIBING}

H. Martin, M. Powell ${ }^{1}$, J.W.L. Puntis, I. Goss. The Children's Centre, The General Infirmary at Leeds; ${ }^{1}$ The Business School, University of Leeds

Aims: To compare the effect of two neonatal PN prescribing systems using Kabi Pharmacia (KB) software. The original ('old') system used SHOs to prescribe using a ward-based networked version of $\mathrm{KB}$, with prescriptions checked and processed in the hospital pharmacy. This system was inflexible, time consuming and complex. The new system involved a joint pharmacist and SHO prescribing system on the ward, with pharmacy input of data.

Methods: Time measurements were collected on the ward and in pharmacy over a 10 month period. SHO opinions and experience were measured using questionnaires at the start and end of rotations. Patient wellbeing was measured by routine biochemical monitoring.

Results: The table relates mean time and activities per day for prescribing.

Abstract 6125

\begin{tabular}{lllllll}
\hline System & $\begin{array}{l}\text { SHO time, } \\
\text { mins }\end{array}$ & $\begin{array}{l}\text { No. of } \\
\text { interruptions }\end{array}$ & $\begin{array}{l}\text { Processing } \\
\text { time, } \text { mins }^{*}\end{array}$ & $\begin{array}{l}\text { No. of } \\
\text { inquiries * }\end{array}$ & $\begin{array}{l}\text { Use of } \\
\text { NSIs * }\end{array}$ & $\begin{array}{l}\text { No. of } \\
\text { alterations }\end{array}$ \\
\hline Old & 30.9 & 1.1 & 21.39 & 1.38 & 0.02 & 0.7 \\
New & 14.46 & 0.15 & 15.1 & 0.70 & 0.20 & 0.3 \\
Saving & +15 & - & +6.3 & & & \\
\hline
\end{tabular}

$\star$ Significant at $\mathrm{p}=0.05 ; \mathrm{NSI}=$ non standard ingredients.

Conclusions: The results show significant time-savings for SHOs and pharmacy processing, plus improved workflows and consistency of prescribing. SHOs preferred the new system and believed it was at least as good as the old in terms of clinical input ( $82 \%$ agreed), nutritional understanding ( $75 \%$ agreed) and quality of patient care $(88 \%)$.

\section{G126 PAEDIATRIC OUTPATIENTS AND USE OF THE INTERNET}

C. Tuffrey, F.O. Finlay. Child Health Department, Newbridge Hill, Bath, UK

Aims: To determine how many families attending paediatric outpatient clinics have access to the internet and have used it to find information about their child's condition, what information they sought, whether they found it useful and whether they discussed it with the paediatrician.

Methods: Questionnaires were distributed to parents attending paediatric outpatients in the Bath clinical area over a six week period Aug-Sept 2000. They were asked to complete them whilst waiting to see the doctor and hand them in before leaving clinic.

Results: 485 questionnaires were completed, a response rate of $84 \%$. Of these, $107(22 \%)$ had looked on the internet for information about the problem for which the child was being seen in clinic that day. $293(62 \%)$ had used the internet previously, $154(33 \%)$ for health information. $332(69 \%)$ owned a computer, and of those, $248(75 \%)$ had internet access. The commonest information sought was information about a diagnosed condition, medical treatments available and long term outcome for their child's problem. $89(84 \%)$ felt the information was useful and $103(99 \%)$ would use the internet again for health information. Only $36(34 \%)$ had, or were planning to discuss the information with the doctor.

Conclusions: We are not aware of any other studies looking at patient internet use in paediatric populations. The internet is an important information resource for parents, which a significant number of families are using. Doctors need to ensure they are able to give parents adequate help and advice in finding accurate, good quality information. 